\title{
Role of extracellular signal-regulated kinase 1/2 signal transduction pathway in insulin secretion by $\beta$-TC6 cells
}

\author{
BEN NIU ${ }^{1,2}$, LIJUAN LIU ${ }^{3}$, HENG SU ${ }^{2}$, XUESHAN XIA ${ }^{1}$, QIU HE ${ }^{2}$, \\ YUE FENG $^{1}$, YUANMING XUE ${ }^{2}$ and XINMING YAN ${ }^{4}$ \\ ${ }^{1}$ Faculty of Life Science and Technology, Kunming University of Science and Technology, Kunming, Yunnan 650500; \\ ${ }^{2}$ Department of Endocrinology, The Affiliated Hospital of Kunming University of Science and Technology, \\ The First People's Hospital of Yunnan, Kunming, Yunnan 650032; ${ }^{3}$ Department of Cadre Ward, \\ WISCO General Hospital, Wuhan, Hubei 430080; ${ }^{4}$ Institute of Basic and Clinical Medicine, \\ Center of Clinical Molecular Biology of Yunnan, The Affiliated Hospital of Kunming University of Science and Technology, \\ The First People's Hospital of Yunnan, Kunming, Yunnan 650032, P.R. China
}

Received February 14, 2015; Accepted February 29, 2016

DOI: $10.3892 / \mathrm{mmr} .2016 .5053$

\begin{abstract}
The present study aimed to investigate the role of the extracellular signal-regulated kinase (ERK)1/2 signal transduction pathway in glucose-stimulated insulin secretion in $\beta$-TC6 mouse pancreatic cells. Insulin production by $\beta$-TC6 cells was stimulated with various concentrations of glucose, which was dose-dependently inhibited by mitogen-activated protein kinase inhibitor PD98059, as indicated by a radioimmunoassay. Furthermore, glucose stimulation enhanced the phosphorylation of ERK1/2, which was dose-dependently inhibited by PD98059, as indicated by western blot analysis. These results indicated that the activation of the ERK1/2 signal transduction pathway may have an important role in glucose-stimulated insulin secretion in $\beta$-TC6 cells.
\end{abstract}

\section{Introduction}

Diabetes is a common disease that poses a serious threat to human health and has an increasing incidence (1). As a metabolic disorder, diabetes results from an inadequate amount of functional $\beta$-cells (2). In type 1 diabetes (T1D),

Correspondence to: Professor Heng Su, Department of Endocrinology, The Affiliated Hospital of Kunming University of Science and Technology, The First People's Hospital of Yunnan, 157 Jinbi Road, Kunming, Yunnan 650032, P.R. China

E-mail: su_hen@hotmail.com

Professor Xueshan Xia, Faculty of Life Science and Technology, Kunming University of Science and Technology, 727 Jingming South Road, Cheng Gong District, Kunming, Yunnan 650500, P.R. China

E-mail: oliverxia@aliyun.com

Key words: diabetes, extracellular signal-regulated kinase 1/2 signal transduction pathway, $\beta$-TC6, insulin $\beta$-cells are destroyed by the immune system (3), while type 2 diabetes (T2D) is associated with insulin resistance and $\beta$-cell dysfunction (4). The reduction of the amount of $\beta$ cells is a common feature of T1D as well as T2D (5). According to Kim and Lee (6), apoptosis of islet $\beta$-cells has a key role in the pathogenesis of diabetes. Glucose-stimulated insulin secretion is one of the important physiological characteristics of islet $\beta$-cells. Extracellular-regulated protein kinase 1/2 (ERK1/2) is an important member of the mitogen-activated protein kinase (MAPK) family. It is activated by multiple extracellular stimuli and regulates cell growth, proliferation, differentiation and death (7). A previous study showed that glucose stimulation can activate the ERK1/2 signal transduction pathway in islet $\beta$-cells, while the role of ERK1/2 activation in insulin secretion has remained elusive (8). The present study aimed to investigate the role of the ERK1/2 signal transduction pathway in glucose-stimulated insulin secretion in $\beta$-TC6 mouse pancreatic cells.

\section{Subjects and methods}

Cell culture. $\beta$-TC6 mouse pancreatic cells (Shanghai Cell Bank of Chinese Academy of Sciences, Beijing, China) were cultured in high-glucose Dulbecco's modified Eagle's medium (HyClone, Logan, UT, USA) with fetal bovine serum, streptomycin and penicillin (Fuzhou Maixin Biotechnology Development Co., Ltd., Fuzhou, China) at $37^{\circ} \mathrm{C}$ in a humidified atmosphere containing $5 \% \mathrm{CO}_{2}$. The medium was replaced once every three days. The cells were passaged at a split ratio of 1:2 every 7-10 days. The survival rate was $>90 \%$ according to trypan blue staining.

Glucose-stimulated insulin secretion. $\beta$-TC6 cells were digested with $0.25 \%$ trypsin and $0.01 \%$ ethylenediaminetetraacetic acid (HyClone). The single-cell suspension $\left(4 \times 10^{4} / \mathrm{ml}\right)$ was seeded into 24-well plates. After $48 \mathrm{~h}$ of growth, the cells were washed by phosphate-buffered saline (PBS; Fuzhou Maixin Biotechnology Development Co., Ltd.) and then 
cultured in serum- and sugar-free KRBH medium (4) $(\mathrm{NaCl}$, 129 mM; KCl, 4.8 mM; $\mathrm{NaHCO}_{3}, 5$ mM; $\mathrm{MgSO}_{4}, 1.2 \mathrm{mM}$; $\mathrm{CaCl}_{2}, 2 \mathrm{M}$ ) at $37^{\circ} \mathrm{C}$ for $30 \mathrm{~min}$. The cells were washed with $\mathrm{KRBH}$ medium and further cultured at $37^{\circ} \mathrm{C}$ for $60 \mathrm{~min}$ in $\mathrm{KRBH}$ medium containing glucose at a concentration of 0 , $1.38,5.5$ or $11.1 \mathrm{mM}$, respectively (9). Finally, the cell supernatant was collected and the insulin concentration was measured using a radioimmunoassay.

Intervention with MAPK inhibitor PD98059. $\beta$-TC6 cells were seeded into six-well plates and incubated for $47.5 \mathrm{~h}$. The MAPK inhibitor PD98059 (Cell Signaling Technology, Inc., Danvers, MA, USA) was added to yield a final concentration of 2,10 or $50 \mu \mathrm{M}$ was added, followed by culture for $30 \mathrm{~min}$. After washing with PBS, the cells were incubated in KRBH medium containing $1.38 \mathrm{mM}$ glucose for $60 \mathrm{~min}$. The cells were then lysed in lysis buffer (Fuzhou Maixin Biotechnology Development Co., Ltd.) and the level of phosphorylated ERK1/2 was measured by western blot analysis. Furthermore, insulin secretion was measured in the supernatant of centrifuged lysate using a radioimmunoassay.

Detection of insulin concentration in the cell supernatant. The insulin concentration in culture supernatant was detected using a radioimmunoassay employing a GC-1200 $\gamma$-radioimmunoassay instrument (USTC Chuangxin Co., Ltd., Hefei, China) and an insulin radioimmunoassay kit (Science and Technology Center, Beijing PLA General Hospital, Beijing, China) according to the manufacturer's instructions. Each group comprised three tubes (the smae supernatant aliquoted into three tubes) and the average value was used as result.

Detection of ERK1/2 phosphorylation levels. The level of ERK1/2 phosphorylation was detected by western blot analysis. After culture with different concentrations of glucose and optionally with PD98059, the $\beta$-TC6 cells were collected and lysed with radioimmunoprecipitation assay buffer mixed with protein phosphatase inhibitor (Fuzhou Maixin Biotechnology Development Co., Ltd.), followed by centrifugation at 1,049 x g at $4^{\circ} \mathrm{C}$ for $5 \mathrm{~min}$. The cell supernatant was collected and the protein concentration was determined. Equal amounts of protein were subjected to $12 \%$ sodium dodecyl sulfate-polyacrylamide gel electrophoresis for $1.5 \mathrm{~h}$ to separate the protein, followed by electrotransfer onto a nitrocellulose membrane (Sigma-Aldrich St. Louis, MO, USA). Following washing of the membrane with PBS (Fuzhou Maixin Biotechnology Development Co., Ltd.), it was probed with the primary antibody against phospho-p44/p42 MAPK antibody (1:1,000; cat. no. sc9101S; Santa Cruz Biotechnology, Inc., Dallas, TX, USA) or $\beta$-actin (1:1,000; cat. no. MX30002; Fuzhou Maixin Biotechnology Development Co., Ltd., Fuzhou, China) at $4^{\circ} \mathrm{C}$ overnight. The secondary antibody (horseradish peroxidaselinked anti-rabbit immunoglobulin G; cat. no. MX3200-2; 1:2,000 dilution; Fuzhou Maixin Biotechnology Development Co., Ltd.) was added, followed by incubation at room temperature for $2 \mathrm{~h}$. After washing of the membrane with PBS, it was incubated with NBT-BCIP solution (Fuzhou Maixin Biotechnology Development Co., Ltd.) in the dark. Images were captured and analyzed using the LAS3000 imaging system (Fuji Film Co., Tokyo, Japan).
Statistical analysis. Values are expressed as the mean \pm standard deviation. SPSS 11.5 software (SPSS, Inc., Chicago, IL, USA) was used for statistical analysis. One-way analysis of variance was performed for comparison among multiple groups. The independent-samples t-test was used for comparison between two groups. $\mathrm{P}<0.05$ was considered to indicate a statistically significant difference.

\section{Results}

Glucose dose-dependently induces insulin secretion by $\beta$-TC6 cells. The insulin levels in the supernatants of $\beta$-TC6 cells treated with $1.38,5.5$ and $11.1 \mathrm{mM}$ glucose were 151.08 \pm 14.34 , $130.67 \pm 11.35$ and $129.05 \pm 4.71 \mu \mathrm{IU} / \mathrm{ml}$, respectively, which were significantly elevated compared with those in the in $0 \mathrm{mM}$ glucose group $(119.77 \pm 3.89 \mu \mathrm{IU} / \mathrm{ml} ; \mathrm{P}<0.01$ or $\mathrm{P}<0.05)$. In addition, the insulin levels in the $1.38 \mathrm{mM}$ glucose group were significantly higher than those in the $11.1 \mathrm{mM}$ glucose group $(\mathrm{P}<0.05)$ (Fig. 1)

Glucose induces ERK1/2 phosphorylation in $\beta$-TC6 cells. As shown in Fig. 2, the level of ERK1/2 phosphorylation was increased in the $1.38,5.5$ and $11.1 \mathrm{mM}$ glucose groups compared with that in the $0 \mathrm{mM}$ glucose group. The level of ERK1/2 phosphorylation was highest in the $1.38 \mathrm{mM}$ glucose group. $\beta$-actin was used as the intrinsic parameter to evaluate the amount of protein.

MAPK inhibitor PD98059 dose-dependently reduces ERK1/2 phosphorylation induced by insulin. After intervention with 2, 10 and $50 \mu \mathrm{M}$ PD98059, the levels of ERK1/2 phosphorylation induced by $1.38 \mathrm{mM}$ glucose stimulation were decreased in a dose-dependent manner (Fig. 3). Furthermore, in the $1.38 \mathrm{mM}$ glucose $+50 \mu \mathrm{M}$ PD98059 group, the phosphorylation of ERK1/2 was almost completely inhibited and below the level in the untreated control group. $\beta$-actin was used as the intrinsic parameter to evaluate the amount of protein and to ensure equal protein loading. Microscopic observation indicated that the growth, viability and morphology of $\beta$-TC6 cells were not affected by PD98059 (results not shown).

PD98059 inhibits glucose-induced insulin secretion by $\beta$-TC6 cells.AsshowninFig.4,PD98059suppressedglucose-stimulated insulin secretion by $\beta$-TC6 cells in a dose-dependent manner. The insulin levels in the $1.38 \mathrm{mM}$ glucose $+10 \mu \mathrm{M}$ PD98059 group and the $1.38 \mathrm{mM}$ glucose $+50 \mu \mathrm{M}$ PD98059 group were $128.27 \pm 6.07$ and $104.10 \pm 9.83 \mu \mathrm{IU} / \mathrm{ml}$, respectively, which were significantly lower than those in the $1.38 \mathrm{mM}$ glucose $+0 \mu \mathrm{M}$ PD98059 group $(151.08 \pm 14.34 \mathrm{U} / \mathrm{ml} ; \mathrm{P}<0.01)$. The insulin level in the $1.38 \mu \mathrm{M}$ glucose $+50 \mu \mathrm{M}$ PD98059 group was lower compared with the untreated group, however, the difference was not significant $(\mathrm{P}>0.05)$.

\section{Discussion}

$\beta$-TC6 cells are derived from the insulinoma cells of a transgenic mouse and express SV40 t-antigen under the control of the insulin promoter. $\beta$-TC6 cells produce pro-insulin I and II, and effectively secret insulin and a small amount of glucagon (10). The threshold of $\beta$ cells refers to the amount 


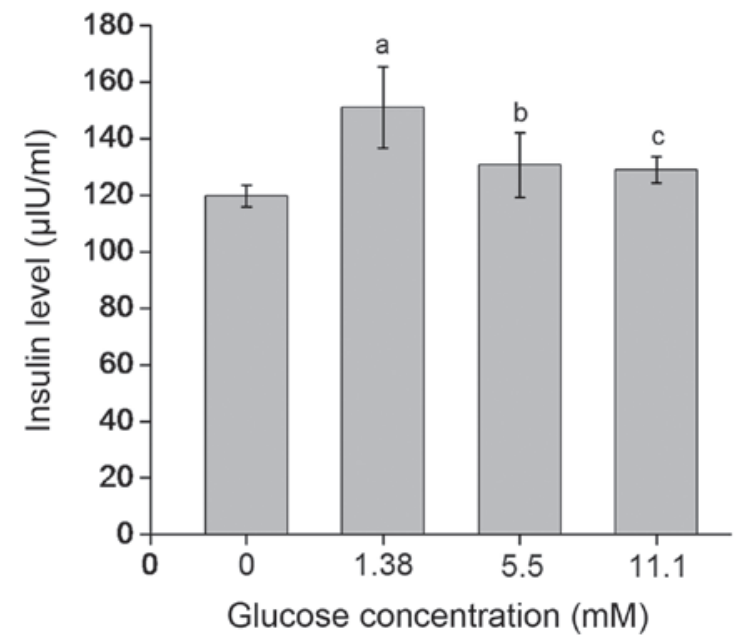

Figure 1. Insulin secretion in $\beta$-TC6 cells stimulated with various concentrations of glucose. ${ }^{\text {a }} \mathrm{P}<0.01$ compared with $0 \mathrm{mM}$ glucose group; ${ }^{\mathrm{b}} \mathrm{P}<0.05$ compared with $0 \mathrm{mM}$ glucose group and $\mathrm{P}>0.05$ compared with $1.38 \mathrm{mM}$ glucose group; ${ }^{\mathrm{P}} \mathrm{P}<0.05$ compared with $0 \mathrm{mM}$ glucose group and $1.38 \mathrm{mM}$ glucose group, and $\mathrm{P}>0.05$ compared with $5.5 \mathrm{mM}$ glucose group.

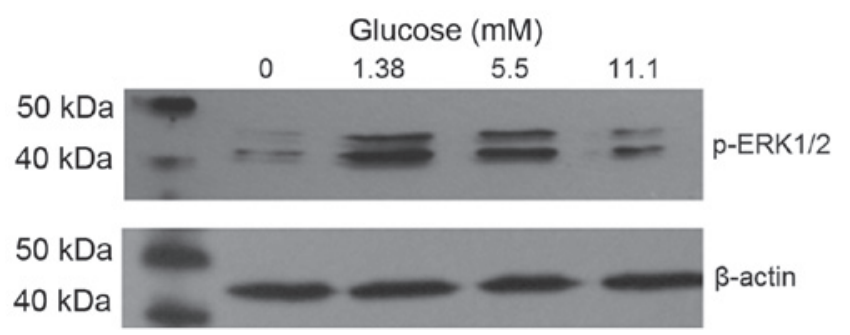

Figure 2. ERK1/2 phosphorylation in $\beta$-TC6 cells induced by glucose as indicated by western blot analysis. p-ERK, phosphorylated extracellular signal-regulated kinase.

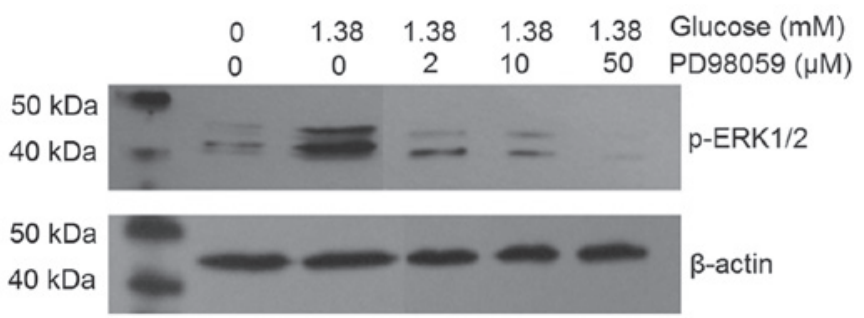

Figure 3. PD98059 inhibits glucose-stimulated ERK1/2 phosphorylation as indicated by western blot analysis. p-ERK, phosphorylated extracellular signal-regulated kinase.

of glucose required for stimulation of insulin production. The maximum threshold of $\beta$-TC6 cells regarding glucose stimulation is lower than that of normal $\beta$-cells, with $1.3-3.0 \mathrm{mM}$ glucose stimulating insulin secretion at peak levels, which are 1.6 times those of sugar-free insulin levels (stimulation index, 1.6) (9). In the present study, stimulation with $1.38 \mathrm{mM}$ glucose led to insulin secretion at peak levels, which were 1.26 times those of sugar-free insulin levels (stimulation index, 1.26). Insulin secretion was stimulated to a lesser extent by higher concentrations of glucose (5.5 and $11.1 \mathrm{mM})$, indicating that $1.38 \mathrm{mM}$ was the most suitable glucose concentration to stimulate insulin secretion.

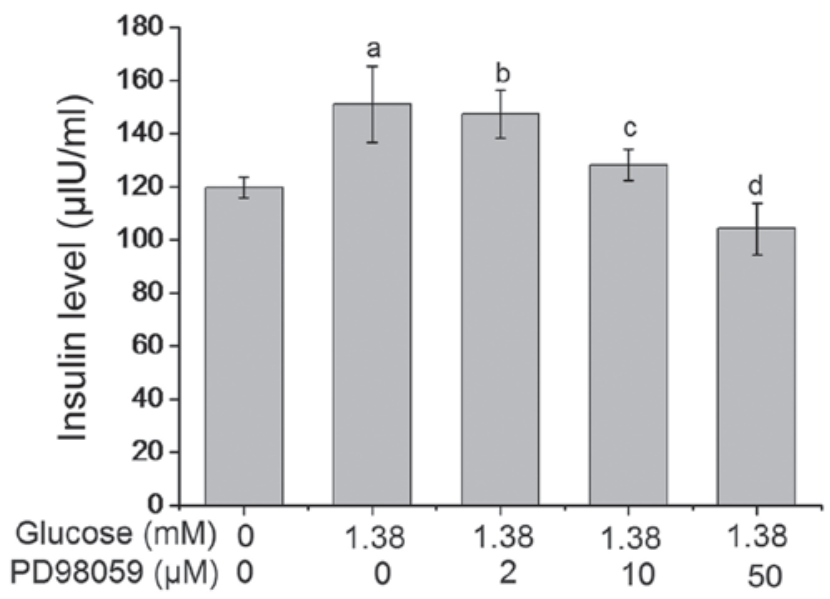

\section{Glucose and PD98059 concentration}

Figure 4. PD98059 treatment inhibits glucose-stimulated insulin secretion in the $\beta$-TC6 cells. ${ }^{\text {a }} \mathrm{P}<0.01$ compared with $0 \mathrm{mM}$ glucose $+0 \mu \mathrm{M}$ PD98059 group; ${ }^{\mathrm{b}} \mathrm{P}>0.05$ when compared with $1.38 \mathrm{mM}$ glucose $+0 \mu \mathrm{M}$ PD98059 group; ${ }^{\mathrm{c}, \mathrm{d}}<0.01$ when compared with $1.38 \mathrm{mM}$ glucose $+0 \mu \mathrm{M}$ PD98059 group.

MAPKs are a class of serine/threonine protein kinases which exist in most cells (11). ERK1/2 are important signaling proteins of the MAPK family that can be activated by extracellular stimuli such as ultraviolet irradiation, high osmotic pressure, heat shock and cytokines (12). A previous study reported that glucose stimulation can activate the ERK1/2 signal transduction pathway (13). Longuet et al (14) found that glucose stimulation can activate the ERK1/2 signal transduction pathway in rats, with the degree of activation regulating the concentration of glucose. In addition, glucose stimulation of the INS-1 rat pancreatic $\beta$-cell line and the MIN6 mouse pancreatic $\beta$-cell line, has been shown to activate the ERK1/2 signal transduction pathway (8). In line with these results, the present study reported that glucose stimulation can activate ERK1/2 signal transduction pathway in $\beta$-TC6 mouse pancreatic cells.

The association between the activation of the ERK1/2 signal transduction pathway and insulin secretion in $\beta$-TC6 cells has not been previously reported, to the best of our knowledge. A study from 1997 indicated that the ERK1/2 signal transduction pathway is not required for glucose-stimulated insulin secretion (15). However, it has been demonstrated that is found that in MIN6 mouse pancreatic $\beta$-cells and primary rat islet $\beta$ cells, blocking of the ERK1/2 signaling pathway reduced glucose-stimulated insulin secretion $(14,16)$. Furthermore, Vlacich et al (17) reported that the protein kinase Pim3 can inhibit the activation of the ERK1/2 signal pathway through suppressor of cytokine-induced signaling 6 and regulates glucose-stimulated insulin secretion. The present study showed that MAPK inhibitor PD98059 dose-dependently inhibited the activation of the ERK1/2 signaling pathway and decreased insulin secretion stimulated by glucose. Thus, it is concluded that the activation of the ERK1/2 signal transduction pathway is may be associated with insulin secretion in $\beta$-TC6 cells. In addition, a previous study (18) indicates that inhibition of the ERK1/2 pathway is associated with the apoptosis of $\beta$ cells. The apoptosis induced by glucose via this pathway may be an underlying mechanism of diabetes development. 
Defects of pancreatic $\beta$-cell function and reduced insulin sensitivity are important pathophysiological features during the onset of diabetes (19). When $\beta$-cell defects appear, the pancreatic island mass and/or volume cannot steadily maintain the glucose metabolism, resulting in high blood glucose levels (20). The present study indicated the role of the ERK1/2 signal transduction pathway in glucose-stimulated insulin secretion, which may represent an important underlying mechanism of the development of diabetes. However, this mechanism remains to be further elucidated and confirmed by future studies.

\section{Acknowledgements}

The present study was supported by the National Natural Science Foundation of China (no. 81560135).

\section{References}

1. Xu Y, Wang L, He J, et al: Prevalence and control of diabetes in Chinese adults. JAMA 310: 948-959, 2013.

2. Shaikh SR, Haas KM, Beck MA and Teague H: The effects of diet-induced obesity on B cell function. Clin Exp Immunol 179: 90-99, 2015.

3. Szablewski L: Role of immune system in type 1 diabetes mellitus pathogenesis. Int Immunopharmacol 22: 182-191, 2014.

4. Mukai E, Toyoda K, Kimura H, et al: GLP-1 receptor antagonist as a potential probe for pancreatic beta-cell imaging. Biochem Biophys Res Commun 389: 523-526, 2009.

5. Mathis D, Vence L and Benoist C: Beta-cell death during progression to diabetes. Nature 414: 792-798, 2001.

6. Kim KA and Lee MS: Recent progress in research on beta-cell apoptosis by cytokines. Front Biosci (Landmark ed) 14: 657-664, 2009.

7. Kumar P, Rao GN, Pal BB and Pal A: Hyperglycemia-induced oxidative stress induces apoptosis by inhibiting PI3-kinase/Akt and ERK1/2 MAPK mediated signaling pathway causing downregulation of 8-oxoG-DNA glycosylase levels in glial cells. Int J Biochem Cell Biol 53: 302-319, 2014.

8. Lawrence M, Shao C, Duan L, McGlynn K and Cobb MH: The protein kinases ERK1/2 and their roles in pancreatic beta cells. Acta Physiol (Oxf) 192: 11-17, 2008.
9. Ohtani M, Oka T, Badyuk M, Xiao Y, Kellar KJ and Daly JW: Mouse beta-TC-6 insulinoma cells: High expression of functional alpha3beta4 nicotinic receptors mediating membrane potential, intracellular calcium and insulin release. Mol Pharmacol 69: 899-907, 2006.

10. Mokhtari D, Al-Amin A, Turpaev K, Li T, Idevall-Hagren O, Li J, Wuttke A, Fred RG, Ravassard P, Scharfmann R, et al: Imatinib mesilate-induced phosphatidylinositol 3-kinase signalling and improved survival in insulin-producing cells: Role of Src homology 2-containing inositol 5'-phosphatase interaction with c-Abl. Diabetologia 56: 1327-1338, 2013.

11. Anbazhagan K, Rabbind Singh A, Isabelle P, Stella I, Céline AD, Bissac E, Bertrand B, Rémy N, Naomi T, Vincent F, et al: Human pre-B cell receptor signal transduction: Evidence for distinct roles of PI3kinase and MAP-kinase signalling pathways. Immun Inflamm Dis 1: 26-36, 2013.

12. Xu S and Kang UG: Cocaine induces ubiquitination of Egr-1 in the rat dorsal striatum. Neuroreport 25: 1362-1367, 2014.

13. Zhang L, Zhang J, Liu X, Liu S and Tian J: Tribbles 3 regulates the fibrosis cytokine TGF- $\beta 1$ through ERK1/2-MAPK signaling pathway in diabetic nephropathy. J Immunol Res 2014: 240396, 2014.

14. Longuet C, Broca C, Costes S, Hani EH, Bataille D and Dalle S: Extracellularly regulated kinases $1 / 2$ (p44/42 mitogen-activated protein kinases) phosphorylate synapsin I and regulate insulin secretion in the MIN6 beta-cell line and islets of Langerhans. Endocrinology 146: 643-654, 2005.

15. Khoo S and Cobb MH: Activation of mitogen-activating protein kinase by glucose is not required for insulin secretion. Proc Natl Acad Sci USA 94: 5599-5604, 1997.

16. Guerra ML, Wauson EM, McGlynn K and Cobb MH: Muscarinic control of MIN6 pancreatic $\beta$ cells is enhanced by impaired amino acid signaling. J Biol Chem 289: 14370-14379, 2014.

17. Vlacich G, Nawijn MC, Webb GC and Steiner DF: Pim3 negatively regulates glucose-stimulated insulin secretion. Islets 2 : 308-317, 2010

18. $\mathrm{Lu} \mathrm{Z}$ and $\mathrm{Xu} \mathrm{S}$ : ERK1/2 MAP kinases in cell survival and apoptosis. IUBMB Life 58: 621-631, 2006.

19. Shiochi H, Ohkura T, Fujioka Y, Sumi K, Yamamoto N Nakanishi R, Matsuzawa K, Izawa S, Ohkura H, Inoue K, et al: Bezafibrate improves insulin resistance evaluated using the glucose clamp technique in patients with type 2 diabetes mellitus: A small-scale clinical study. Diabetol Metab Syndr 6: 113,2014

20. Donath MY, Størling J, Maedler K and Mandrup-Poulsen T: Inflammatory mediators and islet beta-cell failure: A link between Type 1 and Type 2 diabetes. J Mol Med (Berl) 81: 455-470, 2003 